\title{
Refinement of ELISA and its use in early detection of coconut root (wilt) disease
}

\author{
M. Sasikala ${ }^{1}$, V. R. Prakash $^{1}$, V. P. Sapna ${ }^{1}$, M. Mayilvaganan ${ }^{1}$ and \\ Leena. S. Nair ${ }^{1}$
}

\begin{abstract}
Root (wilt) is a major disease of coconut in Kerala and in certain parts of Tamil Nadu. The lasting solution for combating the disease is by evolving root (wilt) disease resistant/tolerant varieties through sustained breeding programmes. Development of visual symptoms of root (wilt) disease is very slow and there is a time lag between infection and symptom expression. Therefore, identification of root (wilt) disease-free palms using early diagnostic techniques (serological techniques) is a basic requirement for the production of quality seedlings. For the mass screening of coconut samples DAC-indirect ELISA has been standardized earlier using antibody raised against pathogen related protein found in diseased palms, but it take about $44 \mathrm{hrs}$ for the completion of the test. In the present investigation using phytoplasma-specific antibodies, test could be refined to make it a more rapid and sensitive one. It has been found that the results could be obtained within 24 hrs with very high sensitivity of $98.4 \%$. Similarly, efficiency of extracting antigen from coconut leaf samples was enhanced by using ART MICCRA D-8 tissue homogeniser. Highest difference in absorbance values between healthy and infected samples was obtained while using carbonate bicarbonate buffer $\mathrm{pH} 9.6$ with additives followed by plain buffer. Thus test could be used to detect phytoplasmal infection in coconut palms even before the appearance of visual symptoms. The modified procedure is being used for identifying disease-free mother palms from disease endemic areas for producing quality seedlings either by crossing programmes or from open pollinated nuts.
\end{abstract}

Key words: Coconut, root (wilt) disease, DAC-indirect ELISA and antiserum.

${ }^{1}$ Central Plantation Crops Research Institute, Regional Station, Krishnapuram-690 533, Kayangulam, Kerala, India. 


\section{Introduction}

Root (wilt), a phytoplasmal disease of coconut (Solomon et al., 1983a) poses serious concern to the coconut growers in Kerala. The disease is considered to be the major threat to coconut production in Kerala and in certain districts of Tamil Nadu bordering Kerala state. Though the disease was initially confined to 3 isolated places in central Kerala (Butler, 1908; Pillai, 1911; Varghese, 1934) now it is prevalent in all the districts with varying intensities (Sreenivasan and Sasikala, 2001). The annual loss due to this disease was valued to Rs. 3,000 million on the basis of 1984 price index (CPCRI, 1985).

Root (wilt) being a phytoplasmal malady, no therapeutic measures are available as on today to control or manage the disease. The major strategy for managing the disease and thereby increasing the production and productivity of coconut in root (wilt) prevalent tracts is to develop high yielding and disease resistant/tolerant varieties through systematic sustained breeding programmes.

Identification of root (wilt) disease-free palms using serological tests is a prerequisite for developing root (wilt) disease resistant/tolerant varieties and the production of quality seedlings using open pollinated nuts (Sasikala et al., 2004).

Flaccidity or inward bending of the leaflets of leaves in the middle and outer whorl is the most consistent visual diagnostic symptom of the disease (Radha and Lal, 1972). Foliar yellowing and marginal necrosis are the other distinguished symptoms. However, the development of root (wilt) symptom is very slow and there is a time lag between infection and symptom expression. Therefore, some of the healthy looking palms in the disease endemic areas might harbour latent infection. To identify root (wilt) disease in its incipient stage, a serological test viz., agar gel double diffusion test (immuno diffusion test) was developed (Solomon et al., 1983b). Although the test is reliable, it requires $96 \mathrm{hrs}$ to get the results and only limited number of samples could be screened at a time.
Subsequently, for mass screening of coconut samples, DAC-indirect ELISA was standardized using a crude antigen and unfractionated antiserum prepared against pathogen-related protein observed in diseased palms; but it required $44 \mathrm{hrs}$ period needed for the completion of the test. Compared to immuno diffusion test, DAC- indirect ELISA is rapid but needs further refinement to make it more rapid and sensitive one. In the present investigations, efforts were made to refine the test to make it more rapid and sensitive one using phytoplasma specific antiserum.

\section{Materials and methods}

\section{Purification of phytoplasma}

Phytoplasma was isolated and purified from the non-chlorophyllous creamy white spear leaf samples collected from coconut palms in the early stage of root (wilt) disease. The procedure followed was described by Mayilvaganan et al. (2001).

\section{Preparation of phytoplasma specific antiserum}

New Zealand white rabbits were employed for the production of polyclonal antiserum to root (wilt) phytoplasma. Briefly, rabbits were immunized intramuscularly with one $\mathrm{ml}$ of purified phytoplasma emulsified with equal volume of Freund's incomplete adjuvant. The emulsion was introduced into the animals through the thigh muscles at seven-day intervals. After four such injections, the rabbits were bled from the marginal vein of the ear on $35^{\text {th }}$ day of the start of immunization. Antiserum recovered from the blood was stored in small vials at $-40^{\circ} \mathrm{C}$ till use after addition of a small pinch of biocide to it. Bleeding was continued at weekly intervals till the titre of the antiserum dropped.

\section{Preparation of test antigen}

Test antigen was extracted from creamy white leaflets drawn from the spear leaves of root (wilt) affected and apparently healthy palms. After deribbing, $0.5 \mathrm{~g}$ of leaf tissues were chopped into small pieces and ground in $0.05 \mathrm{M}$ carbonate bicarbonate buffer ( $\mathrm{pH}$ 9.6) containing 
gelatin (1\%) and ovalbumin (0.2\%). Antigen was extracted with the aid of ART-MICCRA D-8 tissue homogenizer. The extract was filtered through muslin cloth and centrifuged at 5,000 rpm for $10 \mathrm{~min}$ to remove large cell debris. The clarified extract was used as test antigen. Besides carbonate bicarbonate buffer with additives, plain buffer and distilled water were used as extraction medium.

\section{DAC - indirect ELISA}

DAC- indirect ELISA was performed with crude extracts of leaf samples collected from apparently healthy and diseased palms. In this assay, root (wilt) phytoplasma specific antiserum (unfractionated) was used as primary antibody, goat antirabbit IgG conjugated with horseradish peroxidase (Genei, Bangalore) as enzyme conjugate and tetramethyl benzidine/hydrogen peroxidase as substrate. The protocol followed was described by Sasikala et al. (2001) with slight modifications. Briefly, Nunc immunological microtitre plate (Nunc, Denmark) was sequentially loaded with test antigen, blocking agent, phytoplasma specific antibody, enzyme conjugate at a dilution of 1:40,000 and substrate. In between each step, the plate was incubated at $37^{\circ} \mathrm{C}$ and washed with buffer (PBS Tween $\mathrm{pH}$ 7.4). To eliminate the plant antibodies from root (wilt) antiserum, it was cross-absorbed with extracts of leaf taken from healthy palm. After the addition of substrate, the plate was kept at ambient temperature till a bright blue colour got visualized in positive control. The reaction was arrested using $1 \mathrm{~N} \quad \mathrm{H}_{2} \mathrm{SO}_{4}$ and absorbance measured by using $450 \mathrm{~nm}$ filter in VERSA max micro plate reader.

\section{Screening of samples}

Spear leaf samples drawn from apparently healthy elite palms (WCT variety), growing in the disease endemic areas (hot spots) of Alappuzha, Kollam and Ernakulam districts, were employed for the test. These samples were provided by the officials of State Agricultural Department for selecting disease-free elite palms before being used as mother palms for producing quality seedlings. Besides these samples, positive and negative controls were also included in the test. Samples of apparently healthy palms that responded negatively to immuno diffusion test were further subjected to ELISA, the highly sensitive technique to ensure their disease-free nature. Such samples were used as negative controls. Apart from healthy coconut sample, carbonate bicarbonate buffer was also employed as negative control.

\section{Results and discussion}

Phytoplasma-specific antiserum was produced in New Zealand variety rabbits using purified preparations of root (wilt) phytoplasma (Sasikala et al., 2002). High titre antiserum could be produced in about one-year-old rabbits and the antiserum on evaluation has showed the titre which varied from 1: 1,024 to $1: 4,096$.

\section{ELISA}

In DAC-indirect ELISA using phytoplasmaspecific antibodies, a bright blue colour was visualized in infected samples when the ELISA plate was incubated at ambient temperature for 15 min. after the addition of substrate. Samples of negative controls remained colourless or exhibited very faint blue colour. However, while measuring the absorbance, infected samples invariably recorded higher values over that of negative controls (Table 1). Absorbance was measured at an interval of $15 \mathrm{~min}$. Highest difference in the absorbance values between healthy and diseased samples was obtained in the first reading, and subsequently the difference gradually narrowed (Fig. 1). In the present investigation, results could be obtained within 24 hrs whereas in the previous experiment using antibodies against pathogen related protein, only meager difference was observed within the same period (Fig. 2). Efficiency of extracting antigen from coconut leaf tissue was enhanced while using ART-MICCRA D-8 tissue homogenizer for grinding samples (Fig. 3). Similarly, better difference between infected and healthy samples was observed while using $0.05 \mathrm{M}$-carbonate bicarbonate buffer $\mathrm{pH} 9.6$ with additives as extraction medium in comparison to plain buffer without additives. However, when distilled water was used as extraction medium, only very little 
difference was noted between infected and healthy samples (Fig. 4).

\section{Evaluation of sensitivity and specificity}

Sensitivity and specificity of the modified procedure was evaluated with leaf samples collected from 125 coconut palms with root (wilt) symptoms and 56 negative controls. It has been found that very high sensitivity $(98.4 \%)$ and specificity $(96.4 \%)$ were obtained with modified procedure (Table 2 ).

\section{Screening of samples}

A total of 182 elite coconut palms identified in the hot spots of Kollam, Alappuzha and Ernakulam districts were tested by DAC-indirect ELISA using phytoplasma specific antiserum. High absorbance values over the cut off value of negative controls were recorded in 127 samples. Fifty five samples which recorded the absorbance below the cut off value are considered as healthy and these palms are being used as mother palms for producing quality planting materials.

DAC-indirect ELISA had been standardized earlier for the early detection of root (wilt) disease. In this assay, antiserum produced against pathogen-related protein was used as primary antibody. Moreover, glass mortar and pestle were used for extracting antigen from leaf samples. Coconut leaf grindate contains copious amount of tannins, which interact with serum proteins and adversely affect the immunospecificity of the test. Such non-specific reaction between serum proteins and tannins present in the crude extract of coconut leaf was reported earlier (Shanta et al., 1975). To reduce such nonspecific reactions, additives such as gelatin and ovalbumin were incorporated into the extraction medium. Even though significant difference was obtained between healthy and infected samples, it required 44 hrs for the completion of the test.

With the identification of phytoplasma as the causal organism of root (wilt) disease, efforts were made to produce phytoplasma-specific antiserum. The antiserum thus prepared has been used as primary antibody in the present investigation. Due to the fibrous nature of coconut leaf tissue, extraction of antigen from leaf samples is a laborious and time-consuming process. Therefore, in the present study, tissue homogenizer was used for sample extraction. It has been found that the homogenizer could grind leaf tissues as well as the additives thoroughly. As a result, the additives could completely precipitate tannins from the leaf extract and thereby increase the immunospecificity of the test. Perhaps this could also be the reason for enhancing the sensitivity and rapidity of the test. Moreover, phytoplasma-specific antibodies can also enhance the immunospecificity and sensitivity of the test.

\section{Conclusion}

Enzyme Linked Immunosorbent Assay is a well documented technique for the detection of plant diseases and extremely useful for large scale screening of samples. DAC-indirect ELISA standardized earlier for the detection of root (wilt) disease has been refined and the modified procedure described here is simple, highly sensitive, rapid and economic also. The test is being used for the selection of healthy elite parental palms for the production of quality seedlings and confirmation of root (wilt) disease in coconut palms growing in mildly disease affected and new areas. The prompt removal of infected palms from these areas will definitely prevent further spread of the disease. The test can also be used for selecting disease-free seedlings in the nursery.

\section{Acknowledgement}

The authors express their sincere gratitude to the Director, CPCRI, Kasaragod; Head, Crop Protection Division and Head, CPCRI (RS), Kayangulam for providing necessary facilities and encouragement during the course of this study, and gratefully acknowledge Coconut Development Board for providing financial assistance for this study. 
Table 1. Absorbance values of healthy and infected samples

\begin{tabular}{|l|c|c|}
\hline \multirow{2}{*}{ Sl. No. } & \multicolumn{2}{|c|}{ Absorbance } \\
\cline { 2 - 3 } & Healthy & Infected \\
\hline 1 & 0.239 & 0.684 \\
3 & 0.252 & 0.686 \\
4 & 0.289 & 0.670 \\
5 & 0.283 & 0.983 \\
6 & 0.249 & 0.683 \\
7 & 0.259 & 0.923 \\
8 & 0.162 & 0.688 \\
9 & 0.130 & 0.640 \\
10 & 0.154 & 0.646 \\
11 & 0.189 & 0.820 \\
12 & 0.162 & 0.658 \\
13 & 0.245 & 0.775 \\
14 & 0.148 & 0.660 \\
15 & 0.257 & 0.791 \\
\hline
\end{tabular}

(Mean absorbance of 3 replications)

Table 2. Sensitivity and specificity of ELISA

\begin{tabular}{|c|c|c|c|}
\hline \multirow{2}{*}{ Nature of samples } & \multirow{2}{*}{$\begin{array}{c}\text { No. of samples } \\
\text { tested }\end{array}$} & Positive & Negative \\
\cline { 3 - 4 } & & 123 & 2 \\
\hline Infected & 125 & 2 & 54 \\
\hline Negative controls & 56 & & \multicolumn{2}{|c|}{ Reaction } \\
\hline
\end{tabular}

Sensitivity: $98.4 \%$

Specificity: $96.4 \%$ 


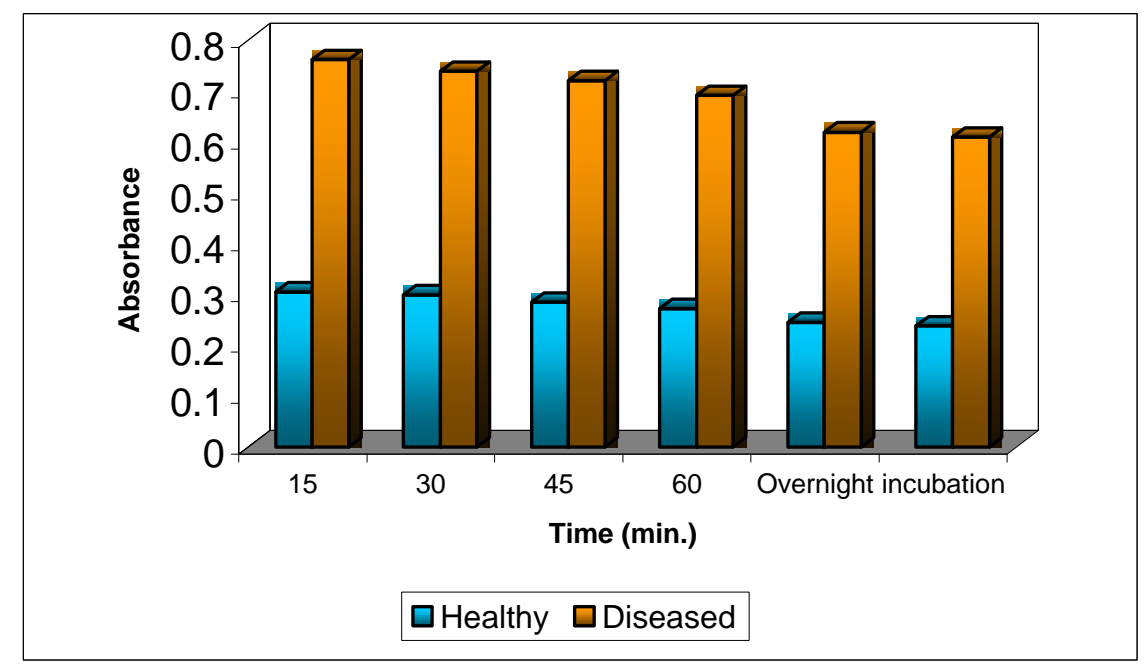

Fig. 1. Effect of incubation period after substrate addition

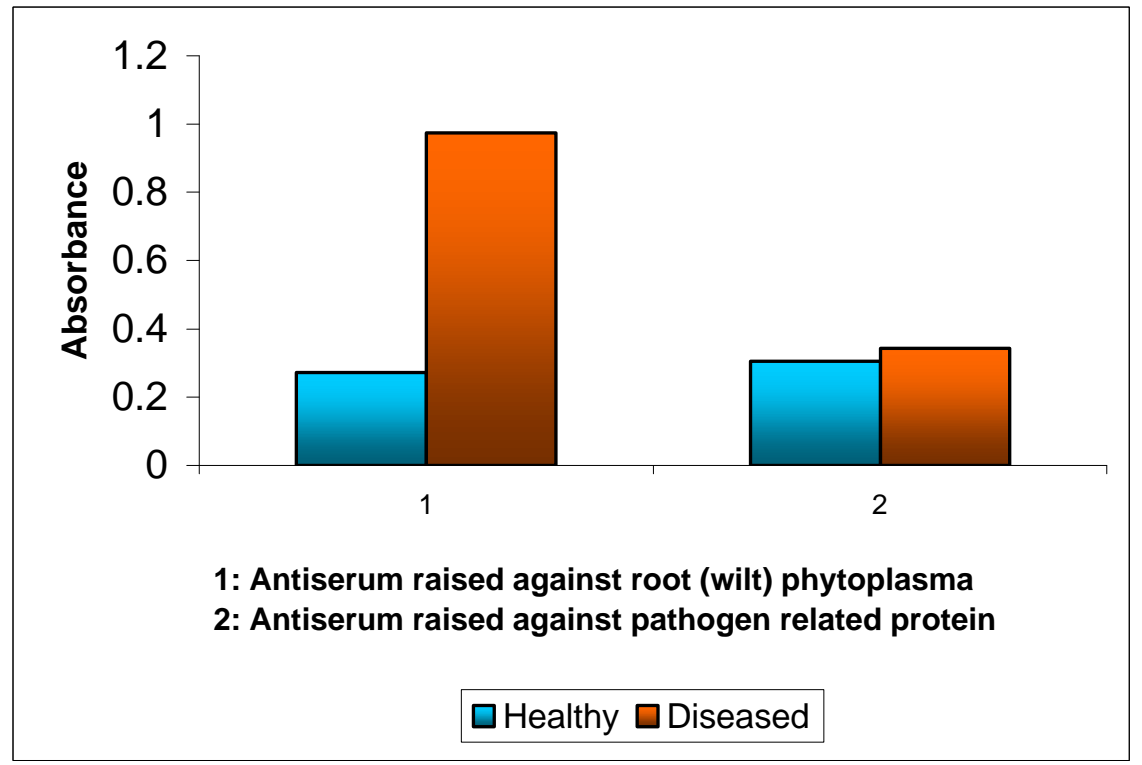

Fig. 2. Sensitivity of antiserum raised against root (wilt) phytoplasma and pathogen-related protein 


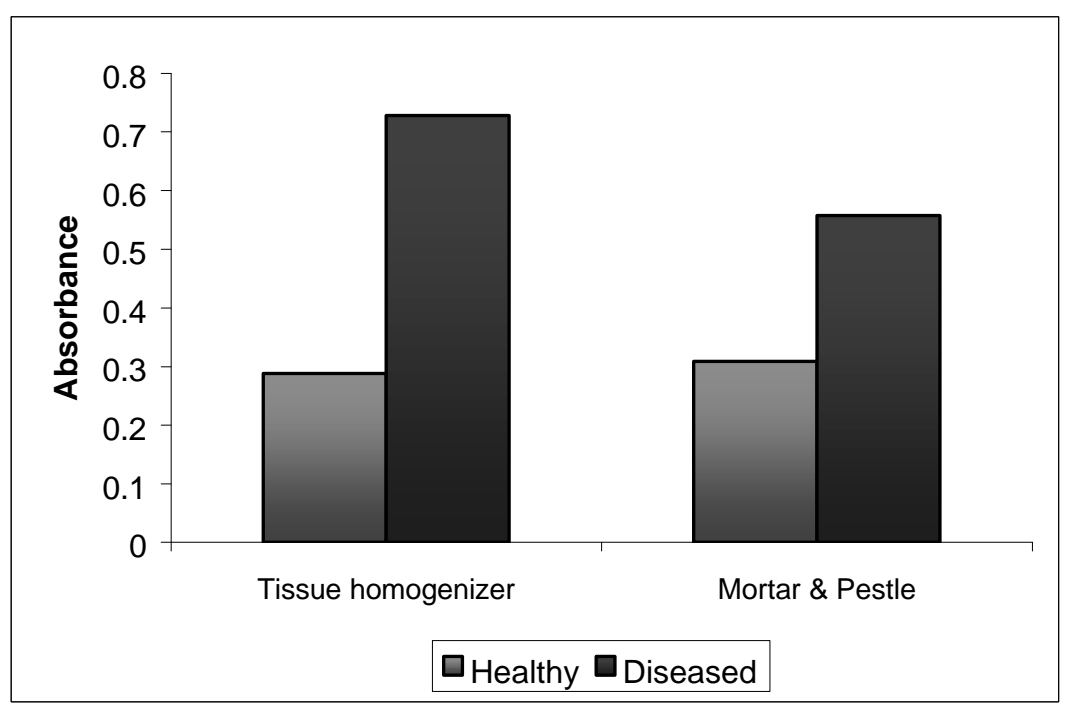

Fig. 3. Efficiency of tissue homogenizer and mortar \& pestle for sample extraction

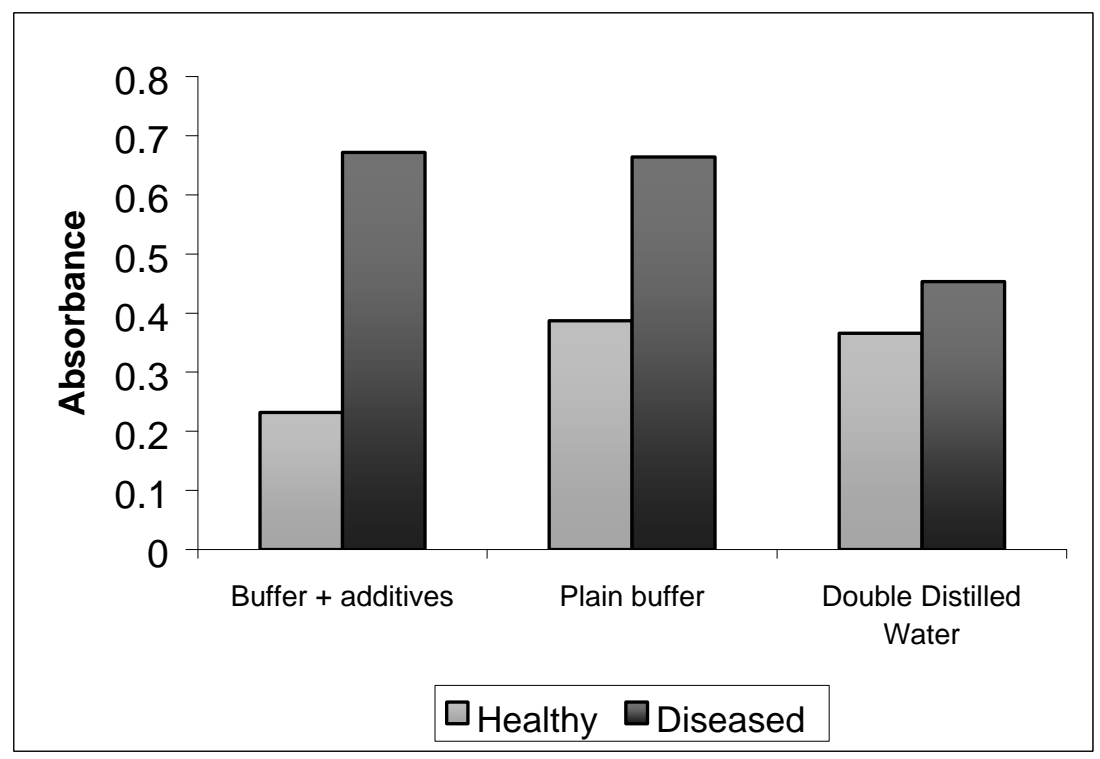

Fig. 4. Effect of extraction medium on intensity of ELISA 


\section{References}

Butler, E.J. 1908. Report on coconut palm disease in Travancore. Agric. Res. Ins. Pusa Bull. 9:23.

CPCRI, 1985. Coconut root wilt diseaseIntensity, production loss and future strategy-A survey report. CPCRI, Kasaragod, 45 pp.

Mayilvaganan, M., Gupta, A. and Chithra, K. R. 2001. Biochemical evidences for purification of phytoplasma of root (wilt) of coconut. J. Plant. Biol. 28(1): 55-60.

Pillai, K.N. 1911. Coconut (in Malayalam). Vidyabhivardhini Press, Quilon, 112 pp.

Radha, K. and Lal, S.B. 1972. Diagnostic symptoms of root (wilt) disease of coconut. Indian J. Agric. Sci. 42: 410-413.

Sasikala, M., Chithra, K.R., Solomon, J.J. and Rajeev, G. 2001. Development of DACindirect ELISA for the rapid detection of coconut root (wilt) disease. Cord 17(2): 23-35.

Sasikala, M., Mayilvaganan, M., Rajeev, G., Chithra, K.R. and Solomon, J.J. 2002. Preparation of root (wilt) phytoplasma specific antiserum and its use in disease detection. National Symposium on Crop Protection and WTO-An Indian Perspective. January 22-25, Kasaragod, p. 24.
Sasikala, M., Prakash, V.R., Ajithkumar, R. and ChandraMohanan, R. 2004. Selection of root (wilt) disease free coconut elite mother palms using serological tests for production of quality planting materials for disease prevalent tracts. Indian Cocon. J. 35(8): 16-19.

Shanta, P., Hariharasubramanian, V. and Gopinathan Pillai, N. 1975. Possible association of tobacco mosaic virus with the root (wilt) disease of coconut. J. Plant. Crops 3: 77-80.

Solomon, J.J., Govindankutty, M.P. and Nienhaus, F. 1983a. Association of mycoplasma like organisms with the coconut root (wilt) disease in India. Z Pflkrankh. Pflschutz. 90: 295-297.

Solomon, J.J., Sasikala, M. and Shantha, P. 1983b. A serological test for the detection of root (wilt) disease of coconut, pp. 401405. In: Coconut Research and Development, N.M. Nayar (Ed.). Wiley Eastern Ltd. New Delhi.

Srinivasan, N and Sasikala, M. 2001. Spread and distribution of coconut root (wilt) disease in the region Theni and Dindigul Districts of Tamil Nadu. Indian Cocon. J. 31(11): 7-11.

Varghese, M.K. 1934. Diseases of the coconut palm. Government Press, Trivandrum, 105 pp. 